It brings before that nerve such an accurate reproduction, so to speak, of the vibrations which were communicated to it at the other end by the vibrations of the molecules of iron, that we have the impression that we see a mass of white hot iron, because the ether was agritated by precisely a mass of white hot iron in the first instancé.

Now, if wc observe any mas s such as this, giving us light in the ordinary way, we get merely the impression of form ; but if we admit such white light to our eye through the prisin; we get it transformed into a band of colour called a spectrum, because, as: we have aiready seen, white light is built up of a gamut of light notes from the lowest note to the bighest; that is--to talk in the language of colour-from the extreme red to the extreme violet, through all those colours which are so gloriously brought before us in the rainbow, and more too.

But this does not happen with all substances.

Let us go now from our mass of white hot iron back to those smallest particles of iron vapour, those ultimate molecules to which I first drew attention. If we subject the light which comes from them to the same treatment, that is, if we allow it to come to our eye through a prism, we find that we don't get the whole gamut of colour represented as in the former case. We only get a light note, so to. speak, here and there. Ordinarily, the phenomenon is presented to us in conscquence of the construction of the spectroscope, by a series of lines, because ordinarily the spectroscope, is so arranged that the vibrations from any set of molecules are made to paint for us images of a fine aperture called a slit, through which the light is made to pass. If the light is discontinuous so far as the gamut of light is concerned, we only get a dight note here and there.: If : it is continuous, the series of images is continuous; and we get what is termed a continuous spectrum, that is, the band of rainbow tints.

Now, mark this well, that when we treat the vapours of all metals that we know of in this way, we find that the arrangement of these bright lines, the arrangement of the images of the slit in other words, is different in the case of the vapour of every metal; so that we may say that no two vapours in Nature have the same colour.

We are now justified in saying, speaking in the lansuage of molecules, that when we drive any chemical substance down to its ultimate fineness, and cause the ultimate molecules of each such chemical substance to vibrate, the vibrations from each chemical substance communicated to the ether and by the ether to our eye are so distinct that if we will take the trouble to record the effects thus obtained, we are for ever afterwards able to recognise the vibrations of that particular molecule, in whatever conditions we see those vibrations thus ren. dered spectroscopically visible to $u s$, whether the mole cules we are examining are in our laboratory; or in the most distant body in the clepths of space.

The blue part of the spectrum which we obtain when we cxamine the light which is communicated to our cye by the vibrations of the finest particles of manganese, to take an example, contains a series of lines absolutely without any arrangement-a broad band here, a single line there, a double line clsewhere, and so on. In iron the arrangement of the lines is perfectly different. They are more numerous, and a detailed examination wothld convince us that it is quite as easy to make as definite a map of such a spectrum, and thus to point out the differences; as it is easy to make a map or drawing of any two things which differ in themselves.

This is sure and certain knowledge. It seems to deal with a condition of things with which the artist will never have to do. . This is so, but the necessity for the statement of these facts will be abundantly seen in the sequelin which I hope-to show that between the two extreme-molecular stages to which I have drawn attention, that wich always gives us white light, and that which gives us coloured light, the colour in no case being the same, we have stages with coloured light which practically is always the same for all bodies.

J. NORMAN·LOCKYER

\section{THE AMERICAN STORM WARNINGS ${ }^{1}$}

TORM movements from west to east over Europe are familiar to your readers, yet I will refer briefly to them here. The chief storm routes are as follows:-From the regions inmediately north of the British Islands to the Norwegian coast and over the Scandinavian Mountains to the Eastern Baltic and Central Russia, thence crossing the Ural Mountains into Siberia. From the British Islands directly to Denmark, North Germany, and : Southern Russia to the regions north of the Caspian Sea, and from the British Channel, over the Netherlands, to Central Furope, passing north of the Alps into the Danube valley, and over the I3lack Sea to $\Lambda$ sia Minor. The influence of position of the area of high pressure southward of the storm track on the direction of the latter is very-great. Whenever the first described route is followed, the pressure is high over. Great Britain, France, and Central Europe, and is falling in the Mediterranean and Northern Africa. If the second route is taken by the storm the barometer is high over Spain and the Mediterranean, giving the zone of low pressure; a generally eastern direction. When the last-described route is followed, the pressure is high in the Atlantic off the coast of France and Spain, leaving a relatively low pressure over Great Britain, Southern Norway, and Sweden, the Western Baltic, and Central Europe.

The heaviest rains occur along the west coast of France and the British Islands, and on the Norway coast. The precipitation lightens castward and south-eastivard to Central Europe, but seems to increase again in the I)anube valley, where the influence of moist air from the Mediterranean basin operates in increasing the energy of the storm. Over the whole field minor disturbances are frequently developed by the movements of the high pressures, which rarcly become scrious storms.

We must regard a knowledge of the general movement of the atmosphere as essential to success in the prediction of the morements of storms, their arrival in different regions, and their character. During the past year.I have followed out and depended on the operation of what I conceive to be a law of atmospheric movement which I deduced from observations of the changes that occur over the areas of the American and European continents

\footnotetext{
I Cortinued from r. 34 .
} 
and of the Atlantic Ocean. I. I was early struck with the incompleteness of a theory which implied the development and movement of detached areas of high and low barometer, especially as such areas must be traced with more or less irregular but distinct outlines. I soon found that in order to justify the appreciation of the term "area" to such figures representing particular conditions, the pressures over large spaces between them should be left practically unaccounted for, and that the most singular alignments of isobars which appear on the weather charts of the United States Signal Service Bureau, and of the European observatories, would not satisfy the want. I became convinced that the lack of continuity in the recognised systems of high and low pressures was a vital fault which affected the whole fabric of weather prediction. Following the', investigation from day to day, I found that these areas, so called, performed their procession across the weather chart with a very striking regularity, and that they maintained relations toward each other which gave me ansidea of their general arrangement and distribution over the field of observation. By a practical application I found that the zone theory of pressures fulfilled all my expectations. By means of the facilities for cabling daily observations from Europe afforded by Mr. Bennett, and through the agency of the Herald ship news department in collecting meteorological data from the logs of vessels that were making West Indian and Transatlantic voyages, I have been able to establish the connection or rather the continuation of the American zones across the Atlantic Ocean and Europe.

Some two months after the Herald storm predictions had begun to attract attention in Europe, the late $M$. Leverrier, as director of the Observatory of Paris, requested that he should be informed fully on the Herald's system. At the same time he expressed the greatest interest in the work, and said that he regarded it as so far successful. In reply to $M$. Leverrier's inquiries I addressed him a letter dated July 10,1877 , on the subject of the Herald's weather warnings, from which I extract the following paragraphs explanatory of the zone law of atmospheric movements :-

"From a system of observations and comparisons which the Herald Meteorological Department has had in operation for over two years, I have been drawn to the conclusion that instead of forming a series of detached areas of erratic morement, the high pressure encircles the earth in a number of unbroken zones, the axes of which alter in direction under the influence of inconstant conditions. Also that between these zones of high pressure lie the zones of low pressure along which the storms take their courses. The normal direction of these zones is nearly parallel with the equator, but they are sometimes so displaced by a combination of influences that their axes form an angle of forty-five degrees and over with that line. I am also satisfied that between the southern extremity of Greenland and the equator there are two zones of low, and perhaps two, but certainly one, of high pressure. The approximate axis of the zone of high pressure lies between the 3 oth and $45^{\text {th }}$ parallels of latitude, but, as I have already stated, this direction is subject to extraordinary variations.

"The zones of high pressure are defined by the isobars of $30^{\circ}$ inches, or $762 \mathrm{~mm}$., and their margins, as well as their axes are undulating constantly under the influence of disturbances moving along the zones of low pressure.
Storm areas or depressions are invariably found within the concave curvatures of these margins, and roll, as it were, along the lines which yield before them more or less readily. I therefore call these the undulating zones of high and low pressure, because of the constant wave motion observable in their axes and margins.

"The outlines of the zones of high and low pressure are governed by the movements and development of the storm centres or depressions. When disturbances of ordinary and uniform energy succeed each other at regular intervals on the northern margin, the axis of the zone of high pressure lying between the 3oth and 45th parallels approaches in alignment to a regular undulation whose general direction is almost parallel with the equator. Modifications of this condition are caused by the relative infrequency of disturbances along the southern margin of the zone. When storms of unequal energy and development occur, the northern undulations become correspondingly irregular, and these reacting on those of the southern margin produce the distortions of outline which sometimes occur. The axis of the zone of high pressure assumes a compound undulatory movement which produces extraordinary variations of the weather within the range of its influence. You will readily perceive how the direction of the course of a southern storm could be changed by the influence of a northern disturbance, and how we can account in some measure for the eccentric movements of these meteors?

"Sometimes two, or even three storm centres, will force their way into the same concavity of the northern margin of the high-pressure zone. When it occurs, the combined energy of the storms enlarges the area of the general depression, absorbs or presses away the obstructing wave of dense atmosphere, or, may be, causes it to temporarily accumulate, with its apex or crest, far into the north. Then according to the resisting power of the wave in front, the storm centre commences to ascend toward the north along a gradually diminishing gradient which has the effect of throwing it on the Norwegian coast, or of giving it a curved course that will bring it from the north-westward toward the British Isles. Hence, although a storm centre may be leaving the Newfoundland coast apparently en route to Ireland, it is impossible to predict where it will reach Europe unless the direction and character of the undulation of high pressure in advance of it and the general trend of the axis of the zone of high pressure are known. These can only be ascertained by a series of daily observations extending over a large area such as that of the United States and Canada on this Continent, or through your international system in Europe and Western Asia. ...

"In the centre, or nearly so, of each wave of high pressure, there is a point where the atmosphere attains its maximum density. This point is recognised ordinarily, and, indeed, properly, as the centre of the area of highest pressure, or anti-cyclonic area. The centres of highest pressure always alternate with the centres of lowest pressure when crossing a given meridian, the air movement around the former being with the hands of the clock, while that around the latter is in the contrary direction. I find that the general movement of the wind along the southern margin of the zone of high pressure is always westward, following the undulations, while that of the northern margin is eastward, also following the wavelines. Now, taking this fact in connection with the geographical position of the zone of highest pressure between the 3oth and 45th parallels, we have on the former line a general westward movement of the wind, corresponding with the trade winds, while on the 45 th parallel, and north of it for some distance, the prevailing winds are from the westward. Again, a series of observations on our Atlantic and Pacific coasts, and in the interior, go to prove beyond question that some regions such as Lower California, and the soutb-eastern 
portion of the Atlantic and Gulf States may be considered as permanently within the wave-lines of the zone of high pressure. This means that the curving of the northern and the southern margins of the zone give to these regions their prevailing winds, which, in the case of Florida and Georgia are called the 'trade-winds.' In the mid-Atlantic, north of the latitude of thirty degrees, there is another permanent area of high presiure and on the southerly side of the area are experienced the 'trade winds.' Now what are these 'trade winds' after all, but the westward flow of the air along the undulating southern margin of the zone of high pressure.

"Sometimes the zone of high pressure becomes compressed to a narrow band between two areas of low pressure, and large areas of high pressure will be formed both east and west of the narrow part of the zone. . . .

"You will naturally desire to know how we reconcile the development and movements of tropical cyclones with the foregoing statements. Although the subject is one that demands a more special treatment than it can receive from me now, I will state that, when at the period of the equinox the solar influence becomes a disturbing element in the meteorology of the equatorial zone, the alignment of the axis of the zone of high pressure becomes a compound curve, so as to present to the westerly flow of the winds and the ocean current a margin of the zone, in the hollow of whose undulations a vortex is developed. This, by cumulative energy, travels atound the wave curre presented to it, and then moves away along the southern margin of the zone of high pressure toward the European coast. The cyclone that devastated Indianola and Galveston in September, 1875, passed almost in a straight line from South Carolina to Valentia, Ireland, and thence probably over Southern Sweden into Northern Russia."

To these remarks I would add that the zones of high pressure sometimes come together but do not merge, and that disturbances moving along the partly-closed zone of low pressure toward the region of contact between the two high-pressure zones, have the necessary energy to divide them again, and thus open a passage eastward between them. On the other hand, the zones close on a depression, and lift it to the higher levels of the atmosphere, where its humidity is condensed into rain that falls over a region whereon the surface-pressures are high.

With the object of utilising the zone law for the purpose of predicting the movement of storms across the oceans and continents, the meteorologist must watch the axial and marginal undulations, and be always aware of the general direction of the former. If this knowledge is possessed the prediction of storm movements becomes a simple matter of close observation and experience. To those who devote their whole attention to the wor' no difficulties can arise, because nature has fixed within certain degrees the limits of deviation which storm movements assume outside the normal courses for each class. The attendant conditions, such as rains, winds, variations of temperature, and humidity, and the presence of superabundant electricity are subject to greater or lesser modifications according as the storms traverse rezions of land, water, mountain, or plain. I would call special attention to the appearance of storm centres over Norway and Eastern Russia, of which no serious indications of their movements were observable in the British Islands and France. Such storms occur always when the pressure is high over the countries last named, and they pass along the northern margin of the zone of high pressure north of the Hebrides or between the Faroe Islands and Iceland, and then move in a south-easterly direction with the undulation into the Baltic and the great plains of Russia, where they sometimes develop considerable energy. This is due to the operation on the eastern slopes of the Scandinavian Mountains of the same causes that combine to produce the north-western storms of Montana Territory.

It is unnecessary to refer to the local phenomena of European storms; they are so fully understood that it is impossible to add anything to the acquired information regarding them. Yet I mention them in the hope that some of the suggestions I have offered in the foregoing may be applied to the study of their development and nature.

JEROME J. COLLINS

\section{SOLAR RADIATION}

Les Radiations chimiques du Soleil. Par M. R. Radau. (Paris : Gauthier-Villars, Imprimeur-Libraire, Quai des Augustins, 1877.)

THE importance of an accurate registration of the comparative intensities of solar radiation is not to be over-estimated at a time when so much diversity of opinion exists regarding the climatic effect which the sun produces upon our earth. Such radiations have been divided into three classes, the heating, the visible, and the chemical or actinic ; and though the whole of these three divisions are for the most part arbitrarily defined, yet such a mode of denoting the rays of light lying between certain limits in the spectrum is on the whole convenient, if the proper mental reservation be made. In the work before us we have an account of the various researches that have been made by different physicists for obtaining a measurement of the comparative intensities of the chemical radiations. An absolute measure of their energy has, up to the present time, been found impracticable, but by noting the amount of change produced by them in what are known as sensitive compounds, a comparison of the otherwise immeasurably small quantity of work that they are capable of performing can be made. The amount of chemical decomposition or combination, caused by the work performed by these rays, is in reality a measure of the work performed by some previous chemical operation together with the infinitely smaller quantity, due to the energy in these radiations. All processes, therefore, which have been employed for the purposes of actinometry, give results which are comparative measures of intensity, and not of absolute energy. Perhaps the nearest approach to an attempt at a measurement of the latter was by means of the chlorine and hydrogen actinometer of Bunsen and Roscoe, certain absorption experiments with which have been well described in the work before us.

In the introductory matter are cited the comparatively recent researches of Vogel of the Berlin Industrial College, in which he shows that by the addition of certain dyes to silver bromide he is able to alter the position of maximum sensibility of this compound to the spectrum. The results of these experiments are certain, but the explanation offered is perhafs more doubtful. It may be remarked, 